OPEN ACCESS

Edited by:

John Varlotto,

Marshall University, United States

Reviewed by:

Chengyu Shi,

New York Proton Center,

United States

Ruijie Yang,

Peking University Third Hospital, China

*Correspondence:

Wen Cheng

hrbchengwen@163.com

Hongtao Hu

huht9099@sohu.com

${ }^{\dagger}$ These authors have contributed equally to this work

Specialty section:

This article was submitted to

Radiation Oncology,

a section of the journal

Frontiers in Oncology

Received: 25 October 2021 Accepted: 24 November 2021 Published: 21 December 2021

Citation:

Jiang S, Liu Z, Tian Y, Zhuang M,

Piao S, Gao Y, Tam A, Hu H and Cheng W (2021) A Comprehensive Evaluation of ZrC Nanoparticle in Combined Photothermal and Radiation Therapy for Treatment of Triple-Negative Breast Cancer.

Front. Oncol. 11:801352. doi: 10.3389/fonc.2021.801352

\section{A Comprehensive Evaluation of ZrC Nanoparticle in Combined Photothermal and Radiation Therapy for Treatment of Triple-Negative Breast Cancer}

\author{
Shan Jiang ${ }^{1 \dagger}$, Zhao Liu $^{1 \dagger}$, Yuhang Tian ${ }^{1}$, Ming Zhuang ${ }^{2}$, Shiqi Piao ${ }^{2}$, Yan Gao ${ }^{3}$, \\ Andrew Tam $^{4}$, Hongtao $\mathrm{Hu}^{2 *}$ and Wen Cheng ${ }^{1 *}$ \\ ${ }^{1}$ Department of Ultrasound, Harbin Medical University Cancer Hospital, Harbin, China, ${ }^{2}$ Department of Radiation Oncology, \\ Harbin Medical University Cancer Hospital, Harbin, China, ${ }^{3}$ School of Chemistry and Chemical Engineering, Harbin Institute \\ of Technology, Harbin, China, ${ }^{4}$ Department of Radiation Oncology, City of Hope National Medical Center, Duarte, CA, \\ United States
}

Because of the difficulty in treating triple-negative breast cancer (TNBC), the search for treatments has never stopped. Treatment opinions remain limited for triple-negative breast cancer (TNBC). The current treatment approach of using photothermal therapy (PTT) is often imprecise and has limited penetration below the surface of the skin. On the other hand, radiation therapy $(\mathrm{RT})$ has its unavoidable disadvantages, such as side effects or ineffectiveness against hypoxic tumor microenvironment (TME). In this study, we proposed the use of ZrC nanoparticles in conjunction with RT/PTT to enhance antitumor and antimetastatic effect. We modified the $\mathrm{ZrC}$ nanoparticle with bovine serum albumin (BSA) and folic acid (FA), sizing desirable about 100nm. The photothermal conversion efficiency was calculated to be $40.51 \%$ and sensitizer enhancement ration (SER) was 1.8. With addition of ZrC NPs, more DNA were damaged in $\gamma-\mathrm{H} 2 \mathrm{AX}$ and more ROS were detected with immunofluorescence. In vitro and vivo, the combined therapy with ZrC NPS showed the best effect of tumor cell inhibition and safety. Our results provide evidence that the combination of ZrC NPs, PT, and RT is effective in of TNBC, making it a great potential application for cancer therapy in clinic.

Keywords: sensitizer, PTT, RT, nanoparticle, breast cancer

\section{INTRODUCTION}

Radiation therapy (RT), combined with surgery and systemic chemotherapy, is the current standard of care treatment for breast cancer $(1,2)$. Using high energy radiation such as X-ray or $\gamma$-ray, RT directly ionizes DNA molecules (3), or indirectly interacts with water, to form reactive oxygen species (ROS) to induce cell apoptosis $(4,5)$. Compared to tumor of squamous cell origin, such as the common type of nasopharyngeal carcinoma, breast adenocarcinoma, especially for triple-negative breast cancer (TNBC), has lower sensitivity to $\mathrm{X}$-ray radiation $(6,7)$. Techniques currently employed to maximize exposure of 
target volume to radiation include intensity modulated radiation therapy and hypofractionation, but risk of acute and late adverse events still need consideration $(8,9)$. How to improve the efficacy of RT for triple-negative breast cancer is a question worth pondering.

Radiosensitizers are agents that increase efficacy of RT, and thereby allow for lower doses of radiation and reducing toxicity to organ at risk (10). Notably, clinical trials demonstrated the potential of high atomic number $(\mathrm{Z})$ nanomaterials as enhancer of radiation to target cancer cells (e.g., gold (10-13), bismuth, wolfram $(14,15)$, platinum, gadolinium (16)) have been exploited. Even though developing radiosensitizers is a promising way to increase the level of efficacy, some difficulties, such as radiation resistance of hypoxic cancer cells, still limit its applications in RT $(14,17)$. To overcome such obstacles, combining RT with phototherapy (PT) to realize a synergistic therapy can open new potentials $(18,19)$. Given the limitations of RT alone, new efforts have explored the potential of combining RT with phototherapy (PT), including photothermal therapy (PTT) and photodynamic therapy (PDT), as a synergistic approach to therapy. The photothermal nanomaterial at tumor site creates local hyperthermia under external near infrared (NIR) irradiation $(20,21)$. The in vivo hyperthermia not only contributes to necrosis or apoptosis of cancer cells, but also creates an oxygen-enriched environment, and in effect reduces radiotherapy resistance (22). In combination with PT, lower dose in RT could be sufficient to kill the tumor and simultaneously enhance systemic antitumor immune response, while high dose RT cause damage to immune system $(23,24)$. Recent evidence has shown that radiation of X-ray and NIR can also be immunomodulatory by altering the microenvironment of the irradiated field $(25,26)$. Since RT and PT are both local treatments as main role, the anti-tumor immunity effects could compensate disadvantages $(24,27)$. Although antitumor immunity induced by RT or PT alone is rarely sufficient to activate systemic anti-tumor immune response, whether combination has the potential to extend the applications beyond a local modality is worth investigating.

It will be very significant if we can construct an ideal "all in one" nanoparticles to act as the sensitizer for both RT and PT that have the following characteristics: (1) good photo-thermal conversion behavior; (2) can act as radiosensitizers to enhance the deposition of irradiation energy; (3) can be specifically targeted to tumors; and (4) is biodegraded (28). In this work, we present a new multifunctional nano agent to be used in combined PT and RT. Using BSA to modify the nanoparticles in order to improve the biocompatibility, as well as tumor-targeted molecule FA (ZrC-BSA-FA, ZrC NPs). Detailed therapeutic strategy by using $\mathrm{ZrC}$ NPs was presented in Scheme 1. At the first part, we characteristic ZrC NPs and then tests were performed to see its excellent thermal storage, thermal stability, thermal conductivity and photo-thermal conversion feature. $\mathrm{ZrC}$ NPs has been an attractive candidate for PT because of its potential as a dual-modality therapy sensitizer, its efficacy as a radio-sensitizer is investigated here for the first time. At the third part we performed experiments to assess the potential to selectively treat TNBC, including vivo and vitro. To further

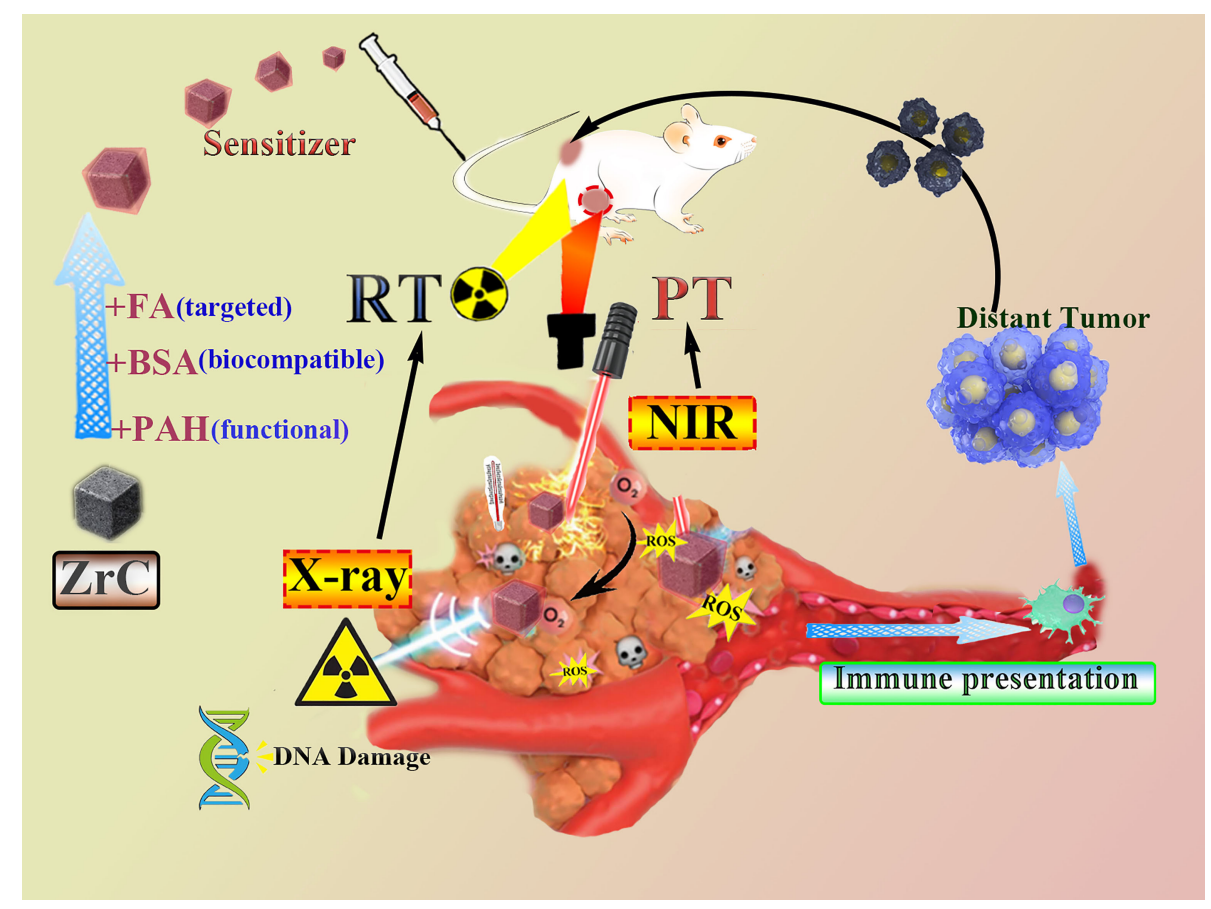

SCHEME 1 | Scheme diagram of radiation therapy combined phototherapy process of this work. 
explain its mechanism, we performed the semiquantitative method to detect tumor apoptosis factors/proliferative factors of tumor. In the last part, we built tumor-bearing mouse model of double tumors to see whether $\mathrm{ZrC}$ NPs with PT and RT in mouse could activate immune response in vitro. Our results provide proof of concept evidence that the combination of $\mathrm{ZrC}$ NPs, PT, and RT is effective for the treatment of TNBC, making it a great potential application for cancer therapy in clinic.

\section{MATERIALS AND CHARACTERIZATIONS}

\section{Materials}

All chemicals and reagents were used as received without further purification.

ZrC nanoparticles were purchased from Shanghai Chaowei Nano Technology Co. Ltd and stored in a desiccator. Folic acid, Poly (allylamine hydrochloride) (PAH, Mw = 17 500), DCFHDA and DPBF were purchased from Sigma-Aldrich. Bovine serum albumin (BSA), calcein-AM, propidium iodide (PI), and 3-(4,5-dimethyl-2-thiazolyl)-2,5-diphenyl-2-H-tetrazolium bromide (MTT) were obtained from Summus. All the antibodies were purchased from Abcam. The $\gamma-\mathrm{H} 2 \mathrm{AX}$ antibody was purchased from Abcam. Phospho-Histone $\gamma$-H2AX (Ser139) (20E3) Rabbit mAb and Antirabbit IgG $(\mathrm{H}+\mathrm{L})$ were provided by Cell Signaling Technology.

$\mathrm{BALB} / \mathrm{c}$ nude mouse and BALB/c mouse were purchased from Beijing Vital River Laboratory Animal Technology Co., Ltd. Animals are fed sterile water and unrestricted food. They were placed in mice room with standard conditions. All the experimental steps adopted in this experiment conformed to the experimental scheme approved by the Key Laboratory for Biomedical Effects of Nanomaterials and Nanosafety (Chinese Academy Sciences, CAS).

\section{Surface Modification Process of ZrC Nanoparticles}

Prior to the modification, $\mathrm{ZrC}$ nanocrystals were heated in $\mathrm{NH} 3$ atmosphere at $850^{\circ} \mathrm{C}$ for $2 \mathrm{~h}$ for full nitridation. Then, the powder was dispersed in water and underwent ultrasonic dispersion for $20 \mathrm{~min}$. The suspension was centrifuged at 4000 $\mathrm{rpm}$ for $5 \mathrm{~min}$ to remove bulk particles. The $\mathrm{ZrCNPs}$ were prepared via electrostatic interaction according to our previously published method with minor modifications. (51), (53) In brief, $\mathrm{ZrC}(6 \mathrm{mg})$ and $\mathrm{PAH}(4 \mathrm{mg})$ were dissolved in $2 \mathrm{~mL} \mathrm{NaCl}$ solution $(0.5 \mathrm{M})$ under ultrasonic dispersion for $20 \mathrm{~min}$ with a mass ratio of 1: 4. Then, the sample was collected by centrifugation (12000 rpm, $5 \mathrm{~min}$ ) and rinsed three times with $\mathrm{NaCl}$ solution $(0.1 \mathrm{M})$ to obtain ZrC@PAH.

After that, ZrC@PAH and BSA with a mass ratio of 1: 3 were dissolved in deionized water and continuously stirred for $4 \mathrm{~h}$ in an ice bath. Finally, the suspension was centrifuged, washed with distilled water and freeze dried, obtaining ZrC@PAH/BSA.

After ZrC@PAH/BSA were prepared, they were mixed with $0.5 \%(\mathrm{wt} / \mathrm{vol})$ of FA-gelatin solution and stirring at room temperature for 24 hours. The FA-functionalized ZrC@PAH/ BSA/FA were collected by centrifugation, washed with Milli-Q water, and redispersed in Milli-Q water for further use.

\section{Characterizations}

The nanostructural features of sample were observed on a JEOL 2100 electron microscope at $200 \mathrm{kV}$ (JEOL Ltd.), including transmission electron microscopy (TEM). The optical behavior of the samples was measured on a spectrophotometer (U-4100, Hitachi). TEM observation was performed using a FEI Tecnai G2 F30 system. The nanoparticles characteristics were determined by XRD (Shimadzu XD-D1). XPS spectra (PerkinElmer PHI 5600) were used to analyze the composition and chemical valence of the samples. The absorption spectra were performed by Cary Series UV-Vis-NIR Spectrophotometer. The hydrodynamic diameter was measured by a Zeta-Sizer (Malvern Nano series). FTIR was acquired by the Excalibur 3100 (Varian). Temperature monitoring was realized with an infrared camera (FLIR System i7).

\section{Photothermal Test}

To examine the photothermal performance of heterogeneous ZrCNPs, different concentrations of CSA solutions were prepared and heated with an $808 \mathrm{~nm}$ laser at different power. An infrared thermal imaging camera (FLIR, A65) was applied to record the change of temperature. The photothermal stability of ZrCNPs was also examined by heating and cooling for 5 cycles. For each cycle, $808 \mathrm{~nm}$ laser was turned on to heat the ZrCNPs solution for 10 minutes and then switched off to allow cooling to room temperature.

$$
\eta=\frac{\mathrm{hS}\left(\mathrm{T}_{\max }-\mathrm{T}_{\text {surr }}\right)-\mathrm{Q}_{\mathrm{d}}}{\mathrm{I}\left(1-10^{-\mathrm{A}} 808\right)}
$$

In the equation $1, S$ is the surface area of the container, $h$ is the heat transfer coefficient, Tmax and TSurr are the equilibrium temperature and ambient temperature of the surroundings, respectively. Qdis is heat dissipated from light absorbed by the quartz sample cell itself, I is the incident laser power $(1.0 \mathrm{~W} \mathrm{~cm}$ 2) and A808 means the optical absorbance of ZrC NPs at $808 \mathrm{~nm}$. Only the hS remains unknown. We introduced a dimensionless driving force temperature to obtain the value of hS.

$$
\begin{gathered}
\theta=\frac{\mathrm{T}-\mathrm{T}_{\text {surr }}}{\mathrm{T}_{\max }-\mathrm{T}_{\text {surr }}} \\
\mathrm{t}=-\tau_{\mathrm{s}} \ln (\theta) \\
h S=\frac{\Sigma m_{i} C_{p, I}}{\tau_{s}}
\end{gathered}
$$

Equation 1.1 shows the cooling stage of the aqueous dispersion, the cooling time $t$ and abide by the equation 1.1, time constant $(\tau s)$ for heat transfer from the system could be determined.

Where $\mathrm{m}, \mathrm{Cp}, \mathrm{I}$ are the mass, heat capacity of water, respectively. According to Equation S1.1, Equation S1.2 and Equation 1.3, the value hS is obtained. The photothermal 
conversion efficiency $(\eta)$ is calculated to be $20.51 \%$ according to Equation 1.

\section{Cell Lines and Cell Culture}

4T1 cells were routinely cultured in DMEM (Corning) medium containing $10 \%(\mathrm{v} / \mathrm{v})$ FBS (Gibco), and $1 \%$ antibiotics (penicillin-streptomycin) (Corning) in a humidified atmosphere at $37^{\circ} \mathrm{C}$ including $5 \% \mathrm{CO} 2$.

\section{Cytotoxicity Assay}

We performed MTT method to illustrate this issue. 4T1 cells and HUVE cells were seeded into 96-well plates $(1 \times 104$ cells per well) and co-incubated with the ZrCNPs dispersion of different concentrations for 24 hours. Then, $20 \mu \mathrm{L}(5 \mathrm{mg} / \mathrm{mL})$ MTT solution was introduced into each well and incubated for another 4 hours. After that, the medium was replaced with dimethyl sulfoxide (DMSO, $150 \mu \mathrm{L}$ per well) for $30 \mathrm{~min}$. A microplate reader (SynergyTMHT, BioTek Instruments Inc., USA) was used to test the optical absorbance at $490 \mathrm{~nm}$.

\section{In Vitro Phototherapeutic Effect}

To explore the optimum sensitizer dose of PTT and RT, the in vitro cell survival rate was evaluated on $4 \mathrm{~T} 1$ cells using a standard MTT assay. The experiment controlled for a single variable at a time and we draw a conclusion:

For RT, cells were treated by linear accelerator of image guided radiotherapy, X-ray radiation set was $6 \mathrm{MV}, 4 \mathrm{~Gy}$ and 300 Does Rate. The height of the liquid level from the underlying cells is $1 \mathrm{~cm}$. For PTT, cells were treated by $808 \mathrm{~nm}$ laser at power density $(2.0 \mathrm{~W} \mathrm{~cm}-2)$. They were divided into six groups, including control, NIR, ZrC+NIR, X-ray, ZrC+X-ray. ZrC $+\mathrm{NIR}+\mathrm{X}$-ray All the experiments were performed for three times. 4T1 cells were seeded into a $35 \mathrm{~mm}$ culture dish $(3 \times$ 105 cells per dish) and incubated at $37^{\circ} \mathrm{C}$ until being nearly $90 \%$ coverage. The culture medium containing $\mathrm{ZrC} \mathrm{NPs}(250 \mu \mathrm{g} \mathrm{mL}-1$ was added into the culture dish and incubated for $6 \mathrm{~h}$ ). After washing with PBS for three times, the fresh culture medium was added into culture dish and the cells were treated. Afterward, the cells were stained using cell doublestaining method (calceinAM and PI) for 20 min to distinguish the living and dead cells, and then observed immediately using fluorescence microscope (Olympus BX53)

\section{Cell Experiments $(\gamma$-H2AX Antibody Recognition Immunofluorescence)}

The cells and anti-phospho-histone $\gamma$-H2AX mouse monoclonal antibody (dilution 1:1000) were incubated together overnight at $4^{\circ} \mathrm{C}$. Next day, the sheep anti-mouse secondary antibody (dilution 1:1000) was incubated with the cells at room temperature for $1 \mathrm{~h}$. DAPI was used to stain cells by labeling the nuclei at room temperature for $5 \mathrm{~min}$. Eventually, the Leica SP5 confocal microscopy was used to observe the cells.

\section{Detection of ROS}

Intracellular ROS generation was detected using DPBF and $\mathrm{H} 2 \mathrm{DCFH}-\mathrm{DA}$ probe, which could be oxidized to produce fluorescent compound of DCF in the presence of ROS. 4T1 cells were seeded into a $35 \mathrm{~mm}$ culture dish and incubated overnight. Afterward, the medium was discarded and cells were incubated with fresh medium containing $\mathrm{ZrC} \mathrm{NPs}(0.5 \mathrm{mg} \mathrm{mL}-1)$ for $4 \mathrm{~h}$. The cells were then washed with PBS. Untreated cells were used as negative control. After that, the cells were stained with H2DCFH-DA $(50 \mu \mathrm{L}, 10 \times 10-3 \mathrm{~m})$ for another $1 \mathrm{~h}$. Thereafter, the cells were washed with PBS and treated in 6 groups as above. The DCF fluorescence images were acquired by fluorescence microscope (Olympus BX53).

\section{Calculation of the Sensitization Enhancement Ratio}

Cell survival fraction of each group was calculated by the ratio of the seeded cells following treatments to form colonies versus the untreated cells as described above. Cell survival fraction and sensitization enhancement ratio (SER) were determined by a classical multitarget single-hit model.and the SER was expressed with the following formulas:

$$
\begin{gathered}
\mathrm{SER}=\frac{\mathrm{D}_{\mathrm{q}}(\text { control group })}{D_{q}(\text { sensitizer group })} \\
D_{q}=\ln (n) \times D_{0} \\
\mathrm{~S}=1-\left(1-\mathrm{e}^{-\frac{\mathrm{D}}{\mathrm{D}_{0}}}\right)^{\mathrm{n}}
\end{gathered}
$$

where $S$ is the survival fraction, $D$ is the radiation dose, $D_{0}$ is the mean lethal dose, and $\mathrm{n}$ is the extrapolation number. Where $\mathrm{D}_{\text {qis }}$ the quasi-threshold dose.

\section{In Vivo Antitumor Effect}

$1 \times 10^{6}$ 4T1 cells were suspended in $100 \mu \mathrm{L}$ PBS mixed with matrix glue $1: 1(\mathrm{~V}: \mathrm{V})$, and were inoculated at the left hind legs of female $\mathrm{BALB} / \mathrm{c}$ nude mice. The tumor-bearing mice were then divided into six groups (five mice each group) when the tumor was about $200 \mathrm{~mm}^{3}$ in size: (a) control, (b) NIR alone, (c) $\mathrm{ZrC}$ NPs+NIR, (d) X-ray alone, (e) ZrC NPs +X-ray and (f). ZrC $\mathrm{NPs}+\mathrm{NIR}+\mathrm{X}$-ray. The $4 \mathrm{~T} 1$ tumor-bearing mice from groups (c), (e), and (f) were administrated nanomaterials intravenously, and the other 3 groups were injected with PBS instead as control. Immobilization scan is operated with Philips CT sim for RT. And RT for mice was performed by Varian IX medical electron linear accelerator immediately after PT. Then, mouse weight and tumor growth were measured after for 14 days. The length and width of tumor were measured with a vernier caliper daily. When the whole experiment finished, all of the mice were sacrificed according to the protocols of Harbin Medical University Cancer Hospital. The tumor and major organs were removed and weighed to calculate the therapy efficacy among six groups.

To study whether the immunity could be triggered by the treatments and how strong it could be on suppressing distant tumors, we designed two experiments to evaluate the therapeutic effect as shown in Figures 6A, E. Two groups of the 4T1 tumorbearing mice were divided randomly: 1) control 2) $\mathrm{ZrC}$ treated $(\mathrm{ZrC}+\mathrm{N}+\mathrm{X})$. In experiment $\mathrm{A}$, we built tumor-bearing mouse 
model with bilateral tumors at -13 th day ( $\mathrm{n}=5$ for each group), and treated primary one (left) at day 0 , leaving the other side distant tumor to be untreated. Thereafter, the tumor volume changes of distant tumor were recorded. The tumor growth rate showed no significant difference between the two groups. In experiment $B$, we implanted the tumor seeds on the other side of mice post treatment and measured their growth rate. As be seen in Figures 6B, F, although the post treatment-implanted tumor grew not as fast as before, distant tumors on treated mice showed more limited tumor growth rate. The logic explanation of the study is the antitumor immune responses of host.

\section{Immunohistochemical Examination}

Immunohistochemistry (IHC) was performed according to the instructions from manufacturer to detect the antibodies, apoptotic factor, multiplication factor, and hypoxia factor in tumor. The anatomical operation of the organs according to standard histological techniques and all the tumor tissues were frozen and then made into $4 \mu \mathrm{m}$ thick serial sections. These paraffin sections were used for IHC staining using standard method. The pathologist was blinded to the identities and analyses of the pathology slides.

\section{Western Blot Analysis}

Total protein was purified and extracted from tissues with RIPA buffer supplemented with proteinase/phosphatase inhibitors (Thermo, Cambridge, MA). Same amounts of total protein were resolved by $10 \%$ SDS-PAGE, followed by transfer onto nitrocellulose membranes (Millipore, Bedford, MA). Anti-Bax (1:500), Bcl-2 (1:500), caspase (1:500), Ki67(1:500), HIF$1 \alpha(1: 500$ (Abcam, USA) primary antibodies were used for the detection

\section{Flow Cytometric Analysis}

Tumors and surrounding tissues were obtained after combined therapy (be specific here). Phenotyping of cells was stained with the following antibodies: FITC-CD3, PE-CD4, PC7-CD8 (BD Phar Mingen, San Diego, CA). Flow cytometric analysis was performed with FACS Calibur (BD Biosciences, Franklin Lakes, NJ)

\section{Histology Analysis}

The mice were sacrificed to collect the tumors and major organs (heart, liver, spleen, lung, and kidney), which were fixed in $4 \%$ paraformaldehyde and embedded with paraffin. The slices of the major organs and tumors of the mice were stained with H\&E for histological analysis. Finally, optical microscope images were acquired by a fluorescent microscope (Olympus BX53).

\section{Hematological Analysis}

Blood $(100 \mu \mathrm{L})$ specimen from the mice were collected and analyzed at 14th day using automatic blood analyzer (HF3800).

Statistic calculated using "Statistical Program for Social Sciences" software (SPSS, version 19.0) and graphpad Prism 8. The final survival fraction curve of each group was generated via a nonlinear fitting using Origin 8.0.

\section{RESULT}

\section{Preparation and Characterization of ZrC NPs}

In this work, we selected $\mathrm{ZrC}$ nanoparticles as the sensitizer to be used in conjunction with RT and PT. To enhance the biocompatibility of $\mathrm{ZrC}$, we alternately coated polyallylamine hydrochloride (PAH, positively charged) and bovine serum albumin (BSA, negatively charged) on the surface of $\mathrm{ZrC}$ via electrostatic interactions. In addition, we used folic acid (FA) for surface modification of the nanoparticles to increase tumor targeting by enhancing the utilization of sensitizer in vivo. The initial zeta potential of unmodified $\mathrm{ZrC}$ nanoparticles is $23.8 \mathrm{mV}$, and after modification with PAH-BSA-FA, the potential changed to $8.61 \mathrm{mV},-12.98 \mathrm{mV}$, and $8.47 \mathrm{mV}$. The change in zeta potential indicates the successful surface modification. This is also supported by the increase of their hydrodynamic size from $95.9 \mathrm{~nm}$ to $121.2 \mathrm{~nm}$ (Figure S1). To determine the dimension of $\mathrm{ZrC} \mathrm{NPs} \mathrm{in} \mathrm{the} \mathrm{aqueous} \mathrm{solution,} \mathrm{the} \mathrm{hydrodynamic} \mathrm{diameter} \mathrm{of}$ $\mathrm{ZrC}$ NPs was tested via dynamic light scattering (DLS) measurement and determined to be $89.6 \pm 1.6 \mathrm{~nm}$ (Figure S2), which is a suitable size for further in vivo administration. The PDI value corresponding to the DLS result is 0.187 . As shown in Figure S3, A is the $\mathrm{ZrC}$ powder dissolved in PBS and $\mathrm{B}$ is the solution of $\mathrm{ZrC}$ NPs. Both solutions were allowed to stand for six hours, and A showed observable precipitation while no obvious change in $\mathrm{B}$, indicating their better stability in physiological solutions.

The TEM image of $\mathrm{ZrC}$ is presented in Figures $\mathbf{1 A}$ and S4, showing that the $\mathrm{ZrC}$ nanoparticles are about $35 \mathrm{~nm}$ in size. The high-resolution TEM (HRTEM), elemental mapping and energy dispersive spectrometer (EDS) were used to further characterize the material. The results demonstrate that the nanoparticles consist of $\mathrm{Zr}$ and $\mathrm{C}$ elements, as proven by an overlay of green $(\mathrm{Zr})$ and red $(\mathrm{C})$ colors in each particle. Next, the chemical valence of the as-prepared $\mathrm{ZrC}$ NPs was determined via XPS analysis Figure 1B. All reflective peaks are well matched with standard cubic ZrC. After deconvolution, the XPS core-level of $\mathrm{Zr} 3 \mathrm{~d}$ orbit results disclose the presence of $\mathrm{Zr} 2+, \mathrm{Zr} 3+$ and $\mathrm{Zr} 4+$ ions in the sample. Classically, the XRD Figure 1C pattern reveals that all the diffractive peaks are attributable to standard cubic $\mathrm{ZrC}$ (PDF\#35-0784). Additionally, Figure 1D shows the powder UV-Vis-NIR spectra of $\mathrm{ZrC}$. ZrC powder exhibits strong and broad absorption in the whole NIR window. Next, FTIR Figure 1E spectrum was applied to detect the chemical compositions of $\mathrm{ZrC} \mathrm{NPs.}$

\section{Photothermal Properties of ZrC}

Photothermal therapy requires photo absorption in the NIR region and the resultant photothermal properties of photoactive materials is particularly important. We first inspected the optical absorption properties of the $\mathrm{ZrC}$ aqueous dispersion by correlating the change in temperature with the concentration of $\mathrm{ZrC}$ over an irradiation time. Different concentrations of $\mathrm{ZrC} \mathrm{NPs}$ $(0.125,0.25,0.5 \mu \mathrm{g} / \mathrm{mL})$ were heated by an $808 \mathrm{~nm}$ NIR laser with various power $(0.5,1,1.5,2 \mathrm{~W} \mathrm{~cm}-2)$ for $10 \mathrm{~min}$, and the 

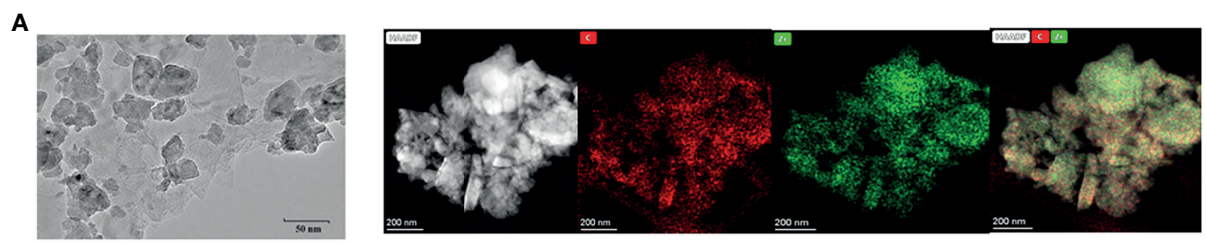

B

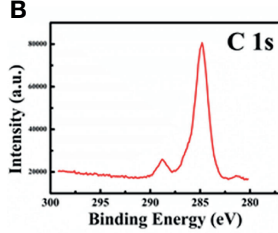

C

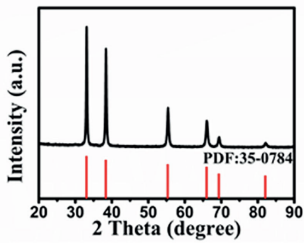

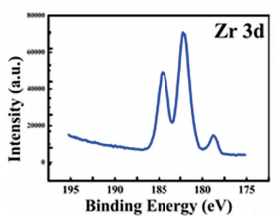

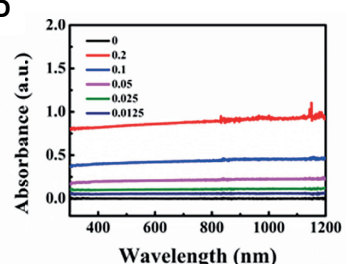

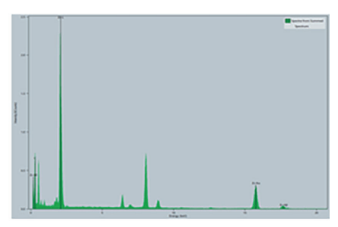

E

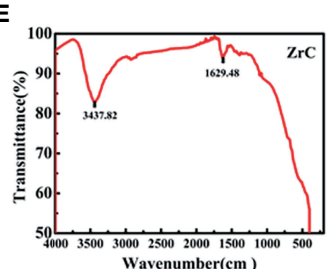

FIGURE 1 | (A) The TEM image and elements mappings image, (B) XPS, (C) XRD PDF:35-0784, (D) UV spectra: optical absorbance of ZrC dispersions with varied concentration, (E) the FTIR spectrums.

transformation in solution temperature was recorded by an infrared thermal imaging camera. As shown in Figure 2A, pure water and $\mathrm{ZrC}$ dispersion of $0.125 \mathrm{mg} / \mathrm{mL}$ showed no significant temperature elevation (about $10^{\circ} \mathrm{C}$ ) after $10 \mathrm{~min}$ of $\mathrm{NIR}$ irradiation. In contrast, the temperature of the $\mathrm{ZrC}$ dispersion of 0.25 and $0.5 \mathrm{mg} / \mathrm{mL}$ increased significantly. The curve in Figure 2B reveals the relationship between temperature increment on the nanoparticle concentration and power, the maximal temperature reached 42.3 and $47.6^{\circ} \mathrm{C}$ for 0.25 and 0.5 $\mathrm{mg} / \mathrm{mL} \mathrm{ZrC}$ dispersion, respectively. The photothermal conversion efficiency was calculated to be $40.51 \%$ (Figure 2C, the calculation details are presented in method and material). The optical density at $808 \mathrm{~nm}$ had a good linear relationship with concentration of $\mathrm{ZrC}$ NPs (the inset of Figure 2C). In addition, the temperature change of $\mathrm{ZrC}$ NPs solution upon NIR on/off irradiation did not change much for five rounds. Shown in Figure 2D, our results revealed photostability of ZrC NPs. Moreover, $\mathrm{ZrC}$ also has a very high absorption in the NIR region, which improves the infrared absorption value of $\mathrm{ZrC}$ NPs to some extent. Such photothermal production and photostability indicated that $\mathrm{ZrC}$ can act as an efficient photothermal conversion agents(PTA).

Inspired by the previous study of X-PDT and PDT, we investigated ROS production from ZrC NPs under NIR and Xray irradiation by using sodium terephthalic as a probe. The 1,3diphenylisobenzofuran (DPBF) and 2'7-dichlorofluores-cin diacetate (DCFH-DA) probes were employed to detect the extracellular and intracellular ROS production, respectively. The DPBF probe for detecting extracellular ROS production lies in its decomposition by ROS. As result, a decrement of DPBF characteristic absorption could be observed accordingly. As displayed in Figure 2E, the absorbance of the DPBF solution with $\mathrm{ZrC}$ decreased meaningfully as irradiation time and X-ray dose increased, suggesting that significant level of ROS was induced by $\mathrm{ZrC}$ under NIR and X-ray. In contrast, the pure water led to very limited ROS generation with the same laser irradiation.

We examined intracellular ROS production in $4 \mathrm{~T} 1$ cells with the use of DCFH-DA probe, which would convert to green fluorescent molecules after being oxidized by ROS, to detect the presence of ROS. As shown in Figure 2F there was no observable green fluorescence from the negative control, while a very weak signal was observed from the NIR group and X-ray group. The fluorescence intensity of sample irradiated by both X-ray and NIR, contained $\mathrm{ZrC}$ NPs, increase $75 \%$ than that of the average of other 5 groups, indicating the ROS producing ability of $\mathrm{ZrC}$ NPs. This result is in agreement with the above-mentioned photocurrent experiment. Therefore, the as-prepared ZrC NPs have potential as both radiosensitizers and photosensitizers for tumor treatment.

\section{In Vitro Cell Cytotoxicity and Phototherapeutic Treatment Combined Radiotherapy}

To determine the optimal nanoparticle concentration for subsequent experiments, we investigated cytotoxicity towards mouse breast cancer 4T1 tumor cells and normal human umbilical vein endothelial cells (HUVECs) using standard MTT assay. was investigated. Cell viabilities are strongly dependent on the concentration of $\mathrm{ZrC}$ NPs. There were no significant differences within or between groups and more than $80 \%$ of the $4 \mathrm{~T} 1$ cells, and HUVECs survived when they were 


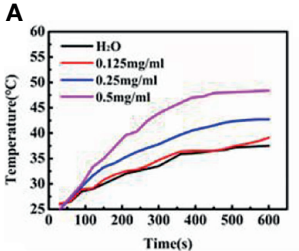

E
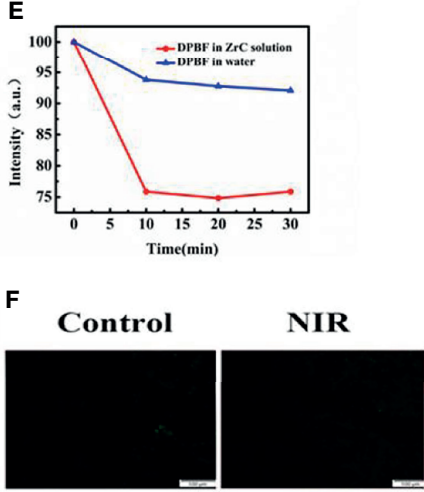

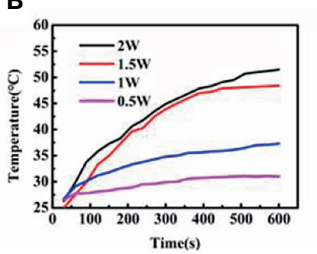

G

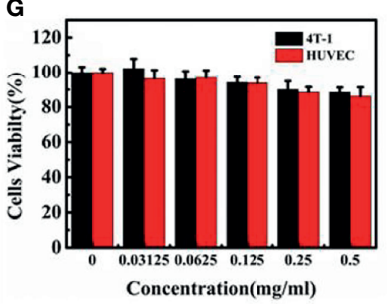

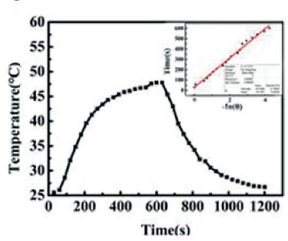

D

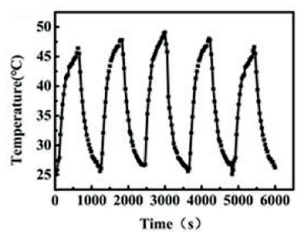

H Time (s)
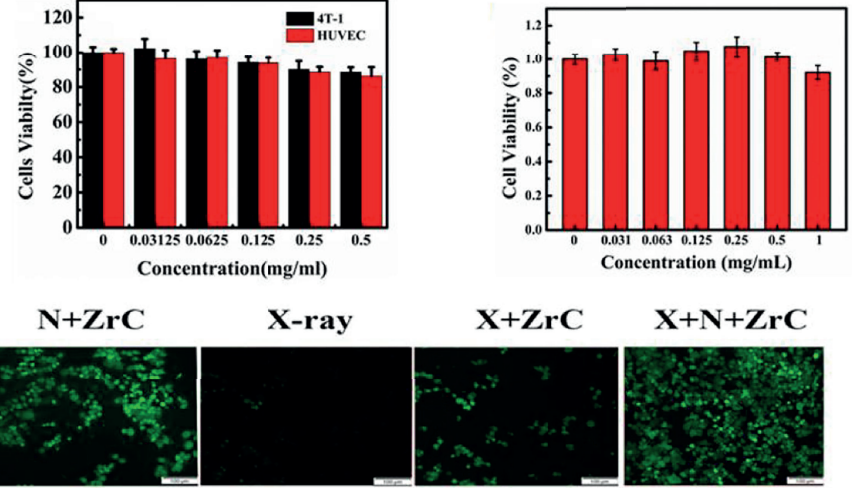

FIGURE 2 | (A) Photothermal temperature curves of ZrC NPs aqueous dispersions at different concentrations. (B) Photothermal temperature curves of ZrC NPs aqueous dispersions at different power of NIR laser. (C) Photothermal test of ZrC dispersion of $0.5 \mathrm{mg} \cdot \mathrm{mL}-1$. (NIR laser: $808 \mathrm{~nm}$, $1.5 \mathrm{~W} \cdot \mathrm{cm}-2$; inset shows plot of time versus - In ( $\Theta$ ); The ZrC dispersion was irradiated with NIR for 10 min and left to natural cooling for another 10 min), (D)Temperature change of ZrC NPs solution at concentration of $0.5 \mathrm{mg} \cdot \mathrm{mL}-1$ over five laser on/off cycles. (808 nm laser irradiation, with a power density of $1.5 \mathrm{~W}$ cm-2. (E) DPBF degradation behavior for ROS detection (NIR laser: $808 \mathrm{~nm}, 1.5 \mathrm{~W} \cdot \mathrm{cm}-2)$; (F) Confocal fluorescence images of reactive oxygen species (ROS) in 6 groups. (G) In vitro cytotoxicity of different concentrations of ZrC NPs to 4T1 cells and HUVE cells, $\mathbf{( H )}$ The biocompatibility of ZrC NPs on proliferation ability of 4T1 cells at different concentration (0, $0.03215,0.0625,0.125,0.5$ and $1 \mathrm{mg} / \mathrm{ml}$ ) after incubation for $48 \mathrm{~h}$. Error bars represent mean \pm SD. (F) The cytotoxicity of ZrC NPs on $4 \mathrm{~T} 1$ and HUVE cells at different concentration $(0,0.03215,0.0625,0.125,0.5$ and $1 \mathrm{mg} / \mathrm{ml})$ after incubation for $24 \mathrm{~h}$.

cultured with $0.5 \mathrm{mg} / \mathrm{mL} \mathrm{ZrC}$ NPs solution (Figure 2G). Figure $\mathbf{2 H}$ demonstrates the effects of different concentration of solution on proliferation of $4 \mathrm{~T} 1$ cells, and then MTT was performed in 48 hours. As shown in the histogram, there was no significant change between the groups, signifying the minimal effect of ZrC NPs on the cells' proliferation ability.

The cytotoxicity results suggest that the concentration of $\mathrm{ZrC}$ NPs applied to tumor cells should be no higher than $0.5 \mathrm{mg} / \mathrm{ml}$. To detect the effective energy level of X-ray for cell experiments, $4 \mathrm{MV}, 6 \mathrm{MV}$ and $12 \mathrm{MV}$ were selected with various radiation dose $(2,4,6,8 \mathrm{~Gy})$. The results show $6 \mathrm{MV}$ group had the statistically significant difference (about $43.47 \%$ ) as demonstrated in Figure S5. From S6, based on the obvious difference of cell surviving fraction between sensitization of $\mathrm{ZrC} \mathrm{NPs} \mathrm{(25.3 \%} \mathrm{in} \mathrm{4Gy),} \mathrm{4Gy} \mathrm{of}$ RT with $6 \mathrm{MV}$ was used for the experiment. PT, $4 \mathrm{~min}$ with $1.5 \mathrm{~W}$ $\mathrm{cm}-2$ was selected, the differences of surviving fraction was $28.6 \%$. We discovered that the final survival rate in these conditions were about $40 \%$ after sensitization. If the single treatment kills most of tumor cells, it will be meaningless to combine additional treatment. Basing on these explorations, we started to compare the killing effect of different therapeutic methods on tumor cells. As shown in Figure 3A, a Live/Dead kit was used to test the activity of 4T1 cells in 6 groups, in which the living cells were stained green and dead cells were stained red. Notably in Figure 3B, with the data analysis of MTT, ZrC NPs played an effective role in sensitization of PT (surviving rate from
$109.32 \%$ to $39.01 \%$ ) while RT(from $45.71 \%$ to $38.66 \%$ ), and the combination therapy of PT/RT with ZrC NPs contributed to the best cancer cell killing efficiency, where the cell survival dropped to $5.16 \%$, demonstrating the powerful synergistic PT and RT effects in vitro. There is a result does not seem to meet expectations that the cell surviving fraction in NIR group was higher than the control group. This is because all the groups were treated under the same conditions, and the room temperature was relatively low during radiotherapy, so cell survival rates were higher with mild PTT. The sensitizer enhancement ration (SER) in this experiment was used to evaluate the radio sensitization efficiency. The SER value of $\mathrm{ZrC}+\mathrm{N}+\mathrm{X}$ group was about 1.8 compared with $\mathrm{X}$-ray group, further confirming that $\mathrm{PT}$ via $\mathrm{ZrC}$ NPs can promote RT function on the cancer cells. However, $\mathrm{ZrC}$ $+\mathrm{X}$ group's SER is about 1.2. Analyze from these data, we found that higher temperature around tumor induced by $\mathrm{ZrC}$ NPs under NIR had obvious sensitization effect on RT while ZrC NPs alone showed weak sensitization effect.

The radiation enhancement was confirmed to be attributed to the process of DNA breaking. Figure 3C showed there were no significant $\gamma$-H2AX fluorescent signals in control and NIR treated groups. Only limited $\gamma-\mathrm{H} 2 \mathrm{AX}$ spots in fluorescent were detected in $\mathrm{N}(\mathrm{ZrC}, \mathrm{X}$-ray, and $\mathrm{X}+\mathrm{ZrC}$ groups. Comparing to other groups, a very high amount of $\gamma-\mathrm{H} 2 \mathrm{AX}$ foci was detected in $\mathrm{N}+\mathrm{X}+\mathrm{ZrC}$ group, indicating significant more DNA breaking due to enhanced $\mathrm{X}$-ray generation by synergistic treatment. There 
A

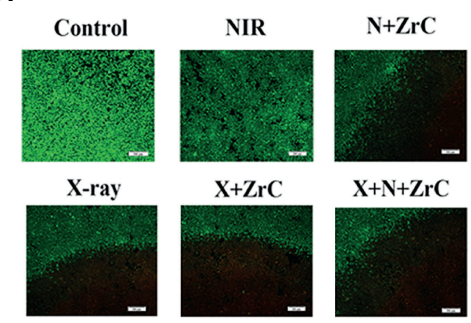

c Control
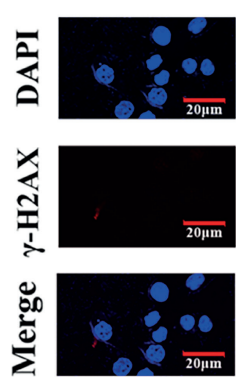

NIR
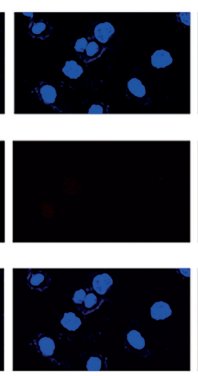

$\mathrm{N}+\mathrm{ZrC}$
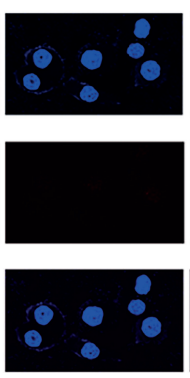

B
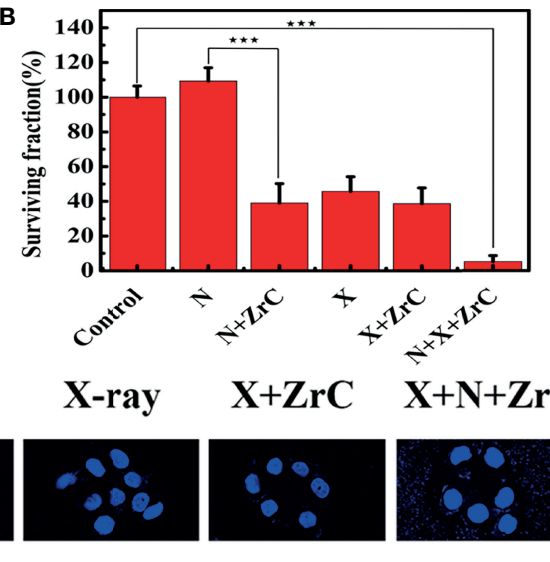

$\mathbf{X}+\mathrm{ZrC} \quad \mathrm{X}+\mathrm{N}+\mathrm{ZrC}$
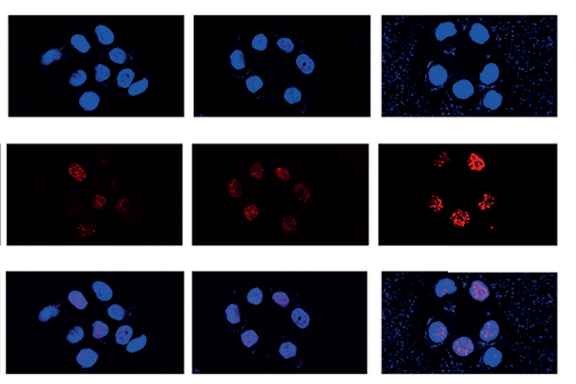

FIGURE 3 | (A, B) live/dead images of 4T1 cells and survival rates analysis after different type of treatment with six groups respectively: Control, NIR, N+ZrC (PT $+\mathrm{ZrC} \mathrm{NPs}), \mathrm{X}$-ray, $\mathrm{X}+\mathrm{ZrC}(\mathrm{RT}+\mathrm{ZrC} \mathrm{NPs}), \mathrm{X}+\mathrm{N}+\mathrm{ZrC}(\mathrm{RT}+\mathrm{PT}+\mathrm{ZrC} \mathrm{NPs})$ in concentrations of $0.5 \mathrm{mg} \mathrm{mg} \cdot \mathrm{mL}-1$ and irradiated with an $808 \mathrm{~nm}$ laser $4 \mathrm{~min}$ with $1.5 \mathrm{~W} \mathrm{~cm}-$ 2 , X-ray with 6MV,4Gy. Error bars represent mean \pm SD. P values based on Student's t-test: *** $p<0.001$. (C) Qualitative representation of DNA fragmentation with different treatment (scale bar: $20 \mu \mathrm{m})$.

results suggest that $\mathrm{ZrC}$ NPs mediated synergistic treatment provides an approach to kill cancer cells with high efficiency. These results were consistent and demonstrated the possibility of using sensitization of PT combined RT in tumors and leading to DNA breakdown in tumor cells.

\section{In Vivo Investigation Anti-Cancer Efficacy}

We further investigated the in vivo photo-therapeutic efficacy of ZrC NPs via a subcutaneous 4T1 tumor-bearing mice model. When the tumor volume reached $\approx 200 \mathrm{~mm} 3,4 \mathrm{~T} 1$ tumor-bearing mice were randomly divided into six groups $(n=5$ for each group) for various treatments: group 1) Control, 2) NIR alone (PT), 3) ZrC +NIR (PT+ZrC NPs), 4) X-ray alone (RT), 5) ZrC $+\mathrm{X}$-ray $(\mathrm{RT}+\mathrm{ZrC}), 6) \mathrm{ZrC}+\mathrm{NIR}+\mathrm{X}$-ray $(\mathrm{RT}+\mathrm{PT}+\mathrm{ZrC} \mathrm{NPs})$. The $\mathrm{Balb} / \mathrm{c}$ nude mice were intravenously (i.v.) injected with $100 \mu \mathrm{L}$ of PBS (group 1) or ZrC NPs (group 3, 5, 6) and then exposed to NIR irradiation ( $808 \mathrm{~nm}, 1.5 \mathrm{~W} \mathrm{~cm}-210 \mathrm{~min})$ or X-ray $(6 \mathrm{MV}$, $6 \mathrm{~Gy})$ at $2 \mathrm{~h}$ post injection for group2,3,4,5 and 6 . First, the surface temperature profiles of tumor region were recorded using an infrared thermal camera during PT at specific points in time. As illustrated in Figures 4A-B, the temperature of tumor site with $\mathrm{ZrC}$ NPs administration rapidly increased to about $57.3^{\circ} \mathrm{C}$ within $10 \mathrm{~min}$ under NIR laser irradiation. However, the temperature of tumor site with only NIR laser irradiation exhibited limited temperature (from $35.5^{\circ} \mathrm{C}$ to $41.5^{\circ} \mathrm{C}$ ) elevation under the same conditions. As temperature increased very limited after $6 \mathrm{~min}$ and this is the meaningful point to be sensitized, so PT's time is settled to be 6 min in mice treatment. Shown in Figure 4C, it is the RT plan for mice. 14 days post-treatment for the body weight and tumor volume. No significant difference was observed in body weight among six groups. However, groups got X-ray irradiation lose a little more weight, most likely due to intestinal mucosa injury after RT when the black mice feces were noticed for about 3 days Figure 4D. To evaluate tumor response, the tumor volume was measured in each group within $14 \mathrm{~d}$. From the comparison of group 2 and 3, group 4 and 5, it shows stronger antitumor effect in the later groups which were injected with $\mathrm{ZrC}$ NPs, indicating that $\mathrm{ZrC}$ NPs played a sensitizer role in both PT and RT, respectively. The relative tumor volume of the mice treated with RT or PT alone was slightly smaller than that in the control group, which illustrated that RT and PT could mildly inhibit the growth of the tumors. However, the mean tumor volume of group 6 was the lowest in all six groups (Figures $4 \mathbf{E}-\mathbf{G}$ ) which indicated that the $\mathrm{ZrC}$ NPs as sensitization materials enhanced PT and RT efficacy and led to substantial better tumor control. Remarkably, although the tumor volume recorded after treatment showed same trend on $\mathrm{ZrC}+\mathrm{N}$ group and $\mathrm{ZrC}+\mathrm{N}+\mathrm{X}$ group in the first few days after treatment, remnant tumor tissues were noticed beneath black scab in $\mathrm{ZrC}+\mathrm{N}$ group as a common phenomenon and showed high local recurrence rate after a week, while in $\mathrm{ZrC}+\mathrm{N}+\mathrm{X}$ group: the interior of the tumor is dominated by residual pus and necrotic tissue.

After PT/RT treatment, the mice show the black scars at their original sites of tumor. To give a better visualization of the killing of tumor, the mice were sacrificed $14 \mathrm{~d}$ later after therapy and histology analysis of tumor tissues was performed via a typical hematoxylin and eosin $(\mathrm{H} \& \mathrm{E})$ method. SI.8shows massive tumor cells necrosis in group $\mathrm{ZrC}+\mathrm{N}$ and $\mathrm{ZrC}+\mathrm{N}+\mathrm{X}$, but not in other 
A

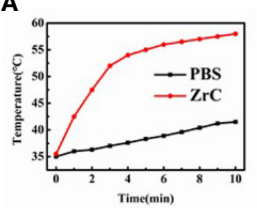

D

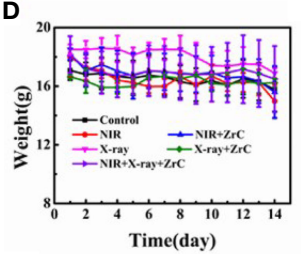

H
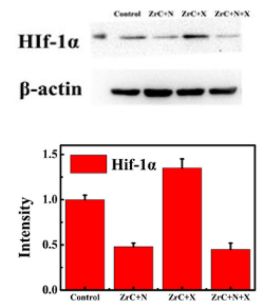

B

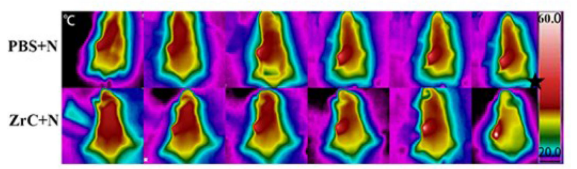

E

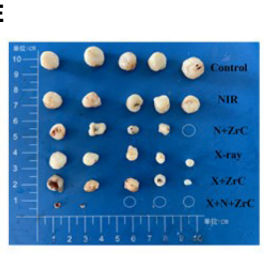

F

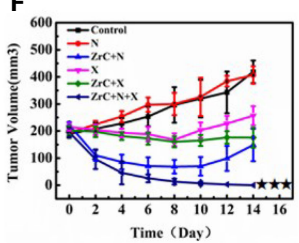

C

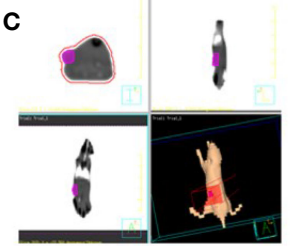

G

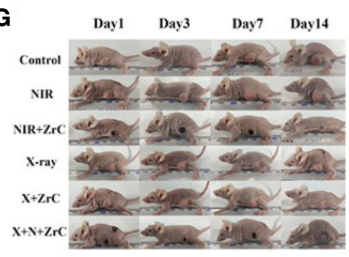

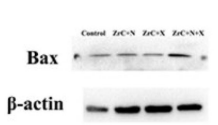
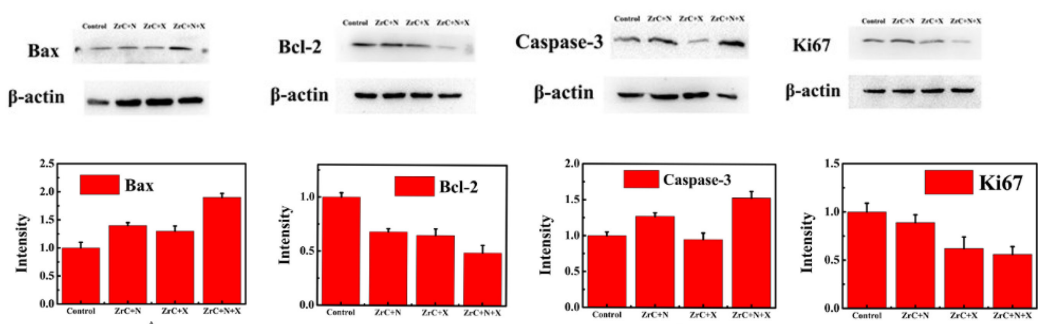

FIGURE 4 | (A)The temperature curves of the tumor site after they were intravenously injected with ZrC NPs (dose $0.5 \mathrm{mg} \mathrm{mL}-1,200 \mu \mathrm{L}$ ) and PBS, respectively, and then exposed to an $808 \mathrm{~nm}$ NIR laser $(1.5 \mathrm{~W} \mathrm{~cm}-2,10 \mathrm{~min})$; (B)Infrared thermal images of tumor-bearing mice while PT. (C) RT plan for mice. (D) The variations in weight of mice in six groups. Error bars represent mean \pm SD. (E) Tumors were cut out at 14 days after treatment from five mice in each group. (F) Tumor volume in six groups were measured after treatment. Error bars represent mean \pm SD. (G) Representative photos of tumor-bearing mice after $14 \mathrm{~d}$ treatment. (H) In control, $\mathrm{NIR}(\mathrm{PT}), \mathrm{ZrC}+\mathrm{N}(\mathrm{PT}+\mathrm{ZrC} \mathrm{NPs}), \mathrm{X}$-ray $(\mathrm{RT}), \mathrm{ZrC}+\mathrm{X}(\mathrm{RT}+\mathrm{ZrC})$ and $\mathrm{ZrC}+\mathrm{N}+\mathrm{X}(\mathrm{RT}+\mathrm{PT}+\mathrm{ZrC}$ NPs) groups, respectively. Protein expression measured by Western Blot of HIF-1a/Bax/Bcl-2/Caspase-3/Ki67 and Intensity expression level of these genes.

four control groups. To provide a deep insight into the mechanism of tumor-growth inhibition, the expression level of bax, bcl-2, caspase-3 which were associated with apoptosis, and proliferation related gene Ki67 were tested by immunohistochemical analysis of tumor tissues and western blot, respectively. As illustrated in Figures $4 \mathbf{H}, \mathbf{5}, \mathrm{ZrC}+\mathrm{N}+\mathrm{X}$ group had higher expression of bax and caspeas-3 and lower expression of bal-2, both associate with cell apoptosis. To evaluate the ability of tumor proliferation, the expression of Ki67, representing the proliferation ability of cells, was examined. We found that the expression level of Ki67 in the combined group was lower. Also, the ability of proliferation in tumor was not inhibited by any single treatment compared to sensitization therapy groups. From the expression of western blot, a conclusion could be drawn that in the groups with X-ray, the proliferation factors showed lower expression while apoptotic factors showed higher in PTT and combined therapy groups, owing to X-ray dose damage to the DNA double-stranded structure and local heat leads to a disruption on cell membrane permeability fist. To further verify the previous hypothesis that the combination of PT and RT could sensitize RT by improving tumor hypoxic microenvironment. Hypoxia-inducible factor $1 \mathrm{a}(\mathrm{Hif}-1 \alpha)$ was tested by western blot and Immunohistochemical analysis from tumor and surrounding tissue. HIF- $1 \alpha$ often expressed in tumors and its transcriptional activity is accurately regulated by the concentration of oxygen, meaning that the stronger Hif- $1 \alpha$ expressed the more severe of hypoxia is. In, it showed that the protein expression of Hif- $1 \alpha$ in group $\mathrm{ZrC}+\mathrm{N}$ was the lowest, and slightly higher in group $\mathrm{ZrC}+\mathrm{N}$ $+\mathrm{X}$ while high in control/X-ray alone/ZrC NPs $+\mathrm{X}$ groups. The expression in group $\mathrm{ZrC}+\mathrm{N}+\mathrm{X}$ was the highest, meaning the RT consumes oxygen in tumor microenvironment produced by PT. The same expression trend of Hif- $1 \alpha$ showed up in immunohistochemical analysis. As the tumor growth inhibition rates were positive correlated to absorption doses and the improvement of hypoxic environment can promote the absorption of radiotherapy $(22,29)$. To summarize the above experimental data in vivo, a conclusion can be drawn that the combination of PT and RT with $\mathrm{ZrC}$ NPs alleviate hypoxia induced resistance of RT and sensitizing tumor tissues to absorb more doses of PT and RT, improving cell apoptosis and tumor suppression rate.

\section{In Vivo Evaluation of Immunoassay}

Recent studies reveal that the free radicals generated by NPs, as well as necrotic tissue debris after PT, are capable of increasing tumor immunogenicity, and thus making these materials possible for cancer immunotherapy $(30,31)$. To study the benefits of ZrC NPs mediated PT and RT, we explored the 


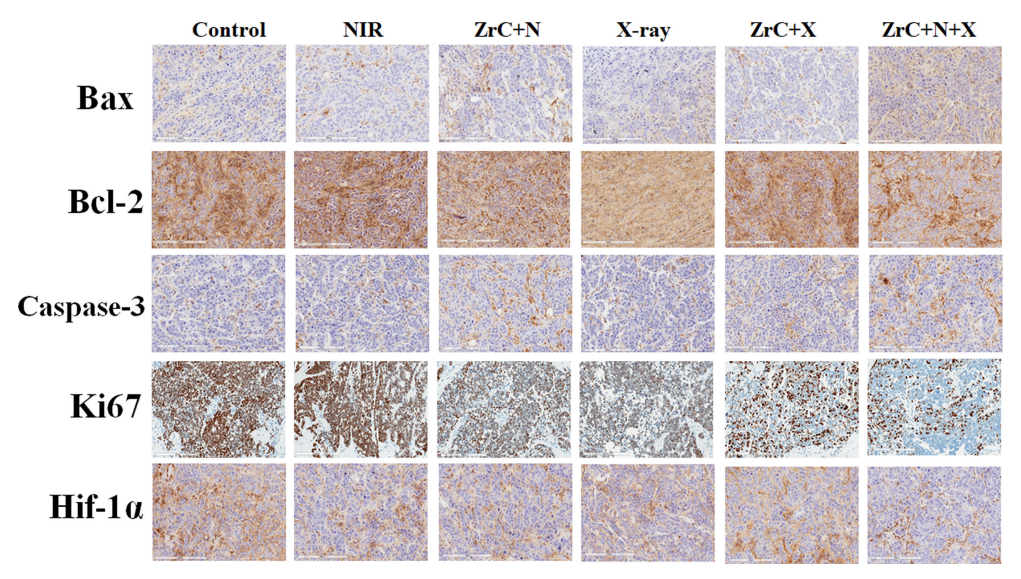

FIGURE 5 | Immunohistochemical analysis of related genes of tumor tissues from six groups of 4T1 tumor-bearing mice after treatment. Furthermore, H\&E staining on the major organs, including heart, kidney, lung, liver and spleen, disclosed no notable damages (i.e., inflammation or necrosis) of all mice (S12). Because of the tumor targeting effect of ZrC NPs, the materials concentrate around the tumor. They result more energy deposition from NIR and X-ray interactions and protect normal tissues while achieving the strongest tumor killing. These results showed a very promising potential which can significantly improve the limitation of single therapy regimen by altering the tumor microenvironment, achieving a safe and efficient elimination of tumor cells.

immunity effect of the material in post treatment mice by: 1) measuring the growing rate of distant tumor on the other side of the body 2) investigating populations of $\mathrm{T}$ cells, analyzed with flow cytometry. 3) immunohistochemical analysis of apoptosis, and proliferation related gene of the distant tumors. The results of the distant tumor inhibition experiment showed that the immune response induced by combined therapy an inhibition effect on new metastatic tumor growth rate after treatment, but had no certain effect on existing distant tumors (32) (Figures 6A, B, E, F, S9). Besides, the first implanted tumor could stimulate some immunity in vivo to some extent.
In addition, we verified above assumption of immune responses further by analysis of flow cytometry. In (Figures 6C, G), the immune cells (tumor-infiltrating cytotoxic $\mathrm{T}$ lymphocytes $\mathrm{CD} 8\left(\mathrm{CD}^{+} \mathrm{CD} 4^{-} \mathrm{CD} 8^{+}\right)$and helper $\mathrm{T}$ lymphocytes $\mathrm{CD} 4$ $\left(\mathrm{CD} 3^{+} \mathrm{CD} 4^{+} \mathrm{CD} 8^{-}\right)$were analyzed in untreated distant tumors from different groups. In experiment $\mathrm{A}, \mathrm{CD} 4$ and $\mathrm{CD} 8$ raised slightly in $\mathrm{ZrC}$ treated group. Relatively, the proportion of CD8 raised more in experiment B while CD4 raised less.

Immunohistochemical analysis of bax, bcl-2, caspase- 3 and $\mathrm{Ki}$ 67 were examined from distant tumor tissues. Shown in Figures 6D, H. there was no obvious difference between two
A Experiment $\mathrm{A}$
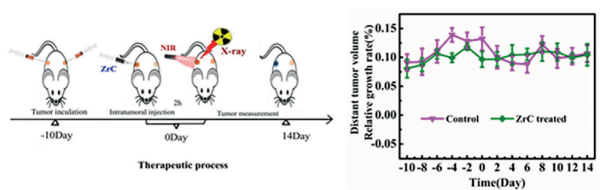

E

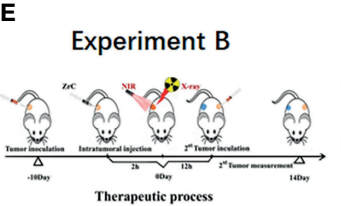

B

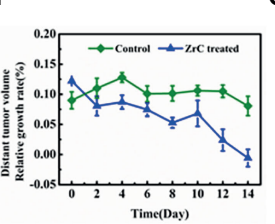

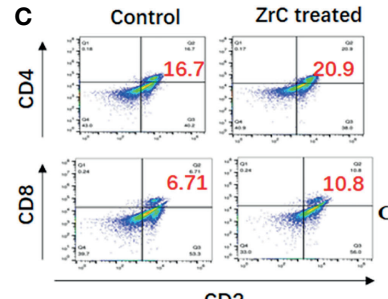

CD3

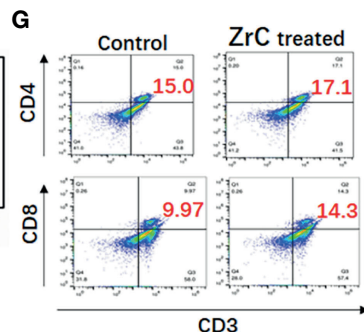

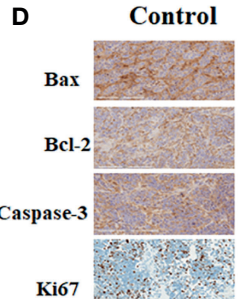

H

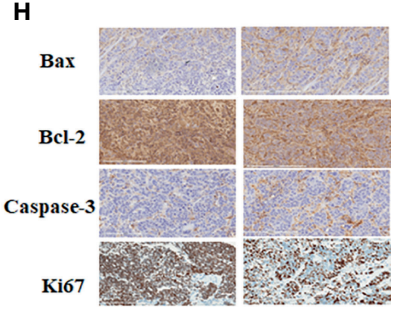

FIGURE 6 | (A, E) Schematic illustration of A/B experiment design and measure the distant tumor volume. (B, F) Relative growth rate of distant tumor volume in two groups. Error bars represent mean \pm SD. (C, G) Representative flow cytometry plots showing different types of T cells in tumor tissue from different groups of mice. (D, H) Immunohistochemical analysis of tumor tissues. 
groups in experiment A. However, in experiment B, similar to caspase-3, bax showed a higher expression in the treated group while bcl-2 showed a lower expression, indicating the enhanced immune system which promoted cancer cell apoptosis. Expression of Ki6 showed the following difference: higher in control group and lower in combined therapy group, confirming that combined treatment impacted the ability of distant tumor proliferation.

\section{In Vivo Safety Evaluation of ZrC NPs}

Lastly, we evaluated the safety of nanomaterials for biomedical application.

No significant abnormal behavior, such as twitching, drowsiness, hobbling, or weight loss were observed in the mice throughout the entire experiment period. No obvious difference was observed in routine blood data after treatment by nanomaterials. To further confirm the treatment safety, major organs of mice from each group were harvested and cut into slices for histochemical analysis through staining with H\&E. As illustrated in S12, histological study of major organs (heart, liver, spleen, lung, kidney) showed no obvious tissue damage or sideeffect in all treatment groups. As for in the blood biochemistry index, besides routine inspection, we measured the hepatic and renal function markers including ALT, AST, BUN and CREA. We separated the mice into 2 groups depending on the application of $\mathrm{ZrC}$ NPs or not. One group included: 1) control, 2) NIR alone, 4) $\mathrm{X}$-ray alone, the other group included:3) $\mathrm{ZrC}$ $+\mathrm{N}, 5) \mathrm{ZrC}+\mathrm{X}, 6) \mathrm{ZrC}+\mathrm{N}+\mathrm{X}$. The white blood cell count increased in group with $\mathrm{ZrC} \mathrm{NPs}$ and that was expected as $\mathrm{ZrC}$ NPs are foreign bodies in the blood that stimulate white blood cell growth. Besides, serum biochemical examination showed slightly increased in groups with $\mathrm{ZrC} \mathrm{NPs,} \mathrm{corresponding} \mathrm{no}$ noticeable renal and hepatic dysfunction induced by the application of $\mathrm{ZrC} \mathrm{NPs,} \mathrm{the} \mathrm{results} \mathrm{showed} \mathrm{the} \mathrm{slightly} \mathrm{increase}$ in S13-14 All results showed that ZrC NPs are safe in vivo.

\section{DISCUSSION}

In TNBC, RT alone has limited curative effect because of the insensitivity of cancer cells to X-ray radiation. To enhance the effect of treatment, this work is the first to present the synthesis and application of brand-new ZrC NPs as sensitization substance for $\mathrm{PT} / \mathrm{RT}$ combination therapy. In this way, to kill the tumor, less does of X-ray and less time of NIR could be enough. Due to the strong photo absorption capability in the NIR region, the synthesized ZrC NPs can generate thermal energy and ROS upon NIR irradiation, simultaneously enhancing RT therapeutic effects. The combined therapy of PT and RT has shown great potential to produce excellent antitumor outcome. Immunohistochemistry, histopathological analysis and western blot were utilized to demonstrate ablation mechanism of tumor. Biocompatibility, ZrC NPs mediated therapy showed no obvious hematotoxicity and systemic toxicity. In addition, combination regimen makes it possible to deliver lower dose PT and RT, relatively, which could avoid the side effects of a single, intense treatment on patients, such as the damage for immune system from high dose RT. Without this drawback, the combination triggered the immune effect and induce tumor immunity for the treatment of metastatic tumors. The investigation attempts to provide some insight into the treatment of TNBC, not only in the sensitization of $\mathrm{RT}$, but also the multiple combinations of treatment.

\section{DATA AVAILABILITY STATEMENT}

The original contributions presented in the study are included in the article/Supplementary Material. Further inquiries can be directed to the corresponding authors.

\section{ETHICS STATEMENT}

This study was approved by the institutional research ethics committee of Harbin Medical University. All animal experiments were performed in strict accordance with the ARRIVE guidelines and were approved by the institutional Animal Care and Use Committee of Harbin Medical University.

\section{AUTHOR CONTRIBUTIONS}

SJ and ZL worked at the sequence alignment, animal experimental, and drafted the manuscript. YT and YG carried out the immunoassays and nanomaterial characterization. SJ, MZ, and SP participated in cell experimental and performed the statistical analysis. $\mathrm{HH}$ carried out the plan of radiation therapy and dose calculation. $\mathrm{HH}$ and WC joined the study's design and performed the statistical analysis. AT participated in the article's text polish and data integration. SJ and ZL contributed equally to this study. All authors contributed to the article and approved the submitted version.

\section{FUNDING}

This work was funded by Science Foundation of Health Commission of Heilongjiang Province (2019052), Innovative scientific research funding project of Harbin Medical University (2020-KYYWF-1471), HAI YAN Science Foundation of Harbin Medical University Cancer Hospital (grant no. JJQN2018-18). HAI YAN Science Foundation of Harbin Medical University Cancer Hospital (grant no. JJQN2021-08).

\section{SUPPLEMENTARY MATERIAL}

The Supplementary Material for this article can be found online at: https://www.frontiersin.org/articles/10.3389/fonc.2021.801352/ full\#supplementary-material 


\section{REFERENCES}

1. Hamilton S, Nichol A, Wai E, Gondara L, Velásquez García H, Speers C, et al. Local Relapse After Breast-Conserving Therapy Versus Mastectomy for Extensive Pure Ductal Carcinoma in Situ $\geq 4 \mathrm{Cm}$. Int J Radiat Oncol Biol Phys (2019) 103(2):381-8. doi: 10.1016/j.jirobp.2018.09.022

2. Possanzini M, Greco C. Stereotactic Radiotherapy in Metastatic Breast Cancer. Breast (Edinburgh Scotland) (2018) 41:57-66. doi: 10.1016/ j.breast.2018.06.011

3. Goldstein M, Kastan M. The DNA Damage Response: Implications for Tumor Responses to Radiation and Chemotherapy. Annu Rev Med (2015) 66:129-43. doi: 10.1146/annurev-med-081313-121208

4. Fang H, Gai Y, Wang S, Liu Q, Zhang X, Ye M, et al. Biomimetic Oxygen Delivery Nanoparticles for Enhancing Photodynamic Therapy in Triple-Negative Breast Cancer. J Nanobiotechnol (2021) 19(1):81. doi: 10.1186/s12951-021-00827-2

5. Gilreath C, Boerma M, Qin Z, Hudson M, Wang S. The Hypoxic Microenvironment of Breast Cancer Cells Promotes Resistance in Radiation Therapy. Front Oncol (2020) 10:629422. doi: 10.3389/fonc.2020.629422

6. Dubsky P, Pinker K, Cardoso F, Montagna G, Ritter M, Denkert C, et al. Breast Conservation and Axillary Management After Primary Systemic Therapy in Patients With Early-Stage Breast Cancer: The Lucerne Toolbox. Lancet Oncol (2021) 22(1):e18-28. doi: 10.1016/S1470-2045(20)30580-5

7. Zhong Y, Xu Y, Zhou Y, Mao F, Lin Y, Guan J, et al. Omitting Radiotherapy is Safe in Breast Cancer Patients $\geq 70$ Years Old After Breast-Conserving Surgery Without Axillary Lymph Node Operation. Sci Rep (2020) 10(1):19481. doi: 10.1038/s41598-020-76663-5

8. Jacobs D, Horeweg N, Straver M, Roeloffzen E, Speijer G, Merkus J, et al. Health-Related Quality of Life of Breast Cancer Patients After Accelerated Partial Breast Irradiation Using Intraoperative or External Beam Radiotherapy Technique. Breast (Edinburgh Scotland) (2019) 46:32-9. doi: 10.1016/j.breast.2019.04.006

9. Gong L, Zhang Y, Liu C, Zhang M, Han S. Application of Radiosensitizers in Cancer Radiotherapy. Int J Nanomed (2021) 16:1083-102. doi: 10.2147/ IJN.S290438

10. Wang H, Mu X, He H, Zhang X. Cancer Radiosensitizers. Trends Pharmacol Sci (2018) 39(1):24-48. doi: 10.1016/j.tips.2017.11.003

11. Yamada M, Foote M, Prow T. Therapeutic Gold, Silver, and Platinum Nanoparticles. Wiley Interdiscip Rev Nanomed Nanobiotechnol (2015) 7 (3):428-45. doi: 10.1002/wnan.1322

12. Guo Z, Zhu S, Yong Y, Zhang X, Dong X, Du J, et al. Synthesis of BSA-Coated Bioi@Bi s Semiconductor Heterojunction Nanoparticles and Their Applications for Radio/Photodynamic/Photothermal Synergistic Therapy of Tumor. Adv Mater (Deerfield Beach Fla.) (2017) 29(44):1704136.1-.12. doi: 10.1002/adma.201704136

13. Wen L, Chen L, Zheng S, Zeng J, Duan G, Wang Y, et al. Ultrasmall Biocompatible WO3- X Nanodots for Multi-Modality Imaging and Combined Therapy of Cancers. Adv Mater (Deerfield Beach Fla.) (2016) 28 (25):5072-9. doi: 10.1002/adma.201506428

14. Zhou R, Wang H, Yang Y, Zhang C, Dong X, Du J, et al. Tumor Microenvironment-Manipulated Radiocatalytic Sensitizer Based on Bismuth Heteropolytungstate for Radiotherapy Enhancement. Biomaterials (2019) 189:11-22. doi: 10.1016/j.biomaterials.2018.10.016

15. Hlouschek J, Ritter V, Wirsdörfer F, Klein D, Jendrossek V, Matschke J. Targeting SLC25A10 Alleviates Improved Antioxidant Capacity and Associated Radioresistance of Cancer Cells Induced by Chronic-Cycling Hypoxia. Cancer Lett (2018) 439:24-38. doi: 10.1016/j.canlet.2018.09.002

16. Liu S, Li H, Xia L, Xu P, Ding Y, Huo D, et al. Anti-Rhoj Antibody Functionalized Au@I Nanoparticles as CT-Guided Tumor Vessel-Targeting Radiosensitizers in Patient-Derived Tumor Xenograft Model. Biomaterials (2017) 141:1-12. doi: 10.1016/j.biomaterials.2017.06.036

17. Sadeghi N, Kok R, Bos C, Zandvliet M, Geerts W, Storm G, et al. Hyperthermia-Triggered Release of Hypoxic Cell Radiosensitizers From Temperature-Sensitive Liposomes Improves Radiotherapy Efficacy In Vitro. Nanotechnology (2019) 30(26):264001. doi: 10.1088/1361-6528/ab0ce6

18. Anand S, Chan T, Hasan T, Maytin E. Current Prospects for Treatment of Solid Tumors via Photodynamic, Photothermal, or Ionizing Radiation Therapies Combined With Immune Checkpoint Inhibition (a Review). Pharm (Basel Switzerland) (2021) 14(5):447. doi: 10.3390/ph14050447
19. Shang T, Yu X, Han S, Yang B. Nanomedicine-Based Tumor Photothermal Therapy Synergized Immunotherapy. Biomater Sci (2020) 8(19):5241-59. doi: 10.1039/D0BM01158D

20. Mauro N, Utzeri M, Varvarà $\mathrm{P}$, Cavallaro G. Functionalization of Metal and Carbon Nanoparticles With Potential in Cancer Theranostics. Molecules (Basel Switzerland) (2021) 26(11):3085. doi: 10.3390/molecules26113085

21. Jiang Q, Li X, Yin C. A Study on Improving the Efficacy of Nanoparticle-Based Photothermal Therapy: From Nanoscale to Micron Scale to Millimeter Scale. Mater (Basel Switzerland) (2021) 14(9):2407. doi: 10.3390/ma14092407

22. Ma T, Liu Y, Wu Q, Luo L, Cui Y, Wang X, et al. Correction to QuercetinModified Metal-Organic Frameworks for Dual Sensitization of Radiotherapy in Tumor Tissues by Inhibiting the Carbonic Anhydrase IX. ACS Nano (2020) 14(2):2553. doi: 10.1021/acsnano.9b09760

23. Poleszczuk J, Enderling H. The Optimal Radiation Dose to Induce Robust Systemic Anti-Tumor Immunity. Int J Mol Sci (2018) 19(11):3377. doi: 10.3390/ijms19113377

24. Chen Z, Wu Z, Muluh T, Fu S, Wu J. Effect of Low-Dose Total-Body Radiotherapy on Immune Microenvironment. Trans Oncol (2021) 14 (8):101118. doi: 10.1016/j.tranon.2021.101118

25. Boustani J, Grapin M, Laurent P, Apetoh L, Mirjolet C. The 6th R of Radiobiology: Reactivation of Anti-Tumor Immune Response. Cancers (2019) 11(6). doi: 10.3390/cancers11060860

26. Li M, Xie D, Tang X, Yang C, Shen Y, Zhou H, et al. Phototherapy Facilitates Tumor Recruitment and Activation of Natural Killer T Cells for Potent Cancer Immunotherapy. Nano Lett (2021) 21(14):6304-13. doi: 10.1021/ acs.nanolett.1c02238

27. Zhang C, Dong J, Shen T, Li Y, Yang Z, Cheng X, et al. [Comparison of the Application Among Intensity-Modulated Radiotherapy, 3D-Conformal Radiotherapy and Conventional Radiotherapy for Locally Advanced Middle-Low Rectal Cancer]. Zhonghua wei chang wai ke za zhi = Chin J Gastrointestinal Surg (2018) 21(12):1414-20.

28. Ma Y, Zhang Y, Li X, Zhao Y, Li M, Jiang W, et al. Near-Infrared II Phototherapy Induces Deep Tissue Immunogenic Cell Death and Potentiates Cancer Immunotherapy. ACS Nano (2019) 13(10):11967-80. doi: 10.1021/acsnano.9b06040

29. Wang S, You Q, Wang J, Song Y, Cheng Y, Wang Y, et al. MSOT/CT/MR Imaging-Guided and Hypoxia-Maneuvered Oxygen Self-Supply Radiotherapy Based on One-Pot Mno-Msio@Au Nanoparticles. Nanoscale (2019) 11 (13):6270-84. doi: 10.1039/C9NR00918C

30. Liu T, Lu T, Yang Y, Chang S, Chen H, Lu I, et al. New Combination Treatment From ROS-Induced Sensitized Radiotherapy With Nanophototherapeutics to Fully Eradicate Orthotopic Breast Cancer and Inhibit Metastasis. Biomaterials (2020) 257:120229. doi: 10.1016/j.biomaterials.2020.120229

31. Dos Santos M, Gouvêa A, de Moura L, Paterno L, de Souza P, Bastos A, et al. Nanographene Oxide-Methylene Blue as Phototherapies Platform for Breast Tumor Ablation and Metastasis Prevention in a Syngeneic Orthotopic Murine Model. J Nanobiotechnol (2018) 16(1):9. doi: 10.1186/s12951-018-0333-6

32. Han R, Xiao Y, Yang Q, Pan M, Hao Y, He X, et al. Ags NanoparticleMediated Multiple Ablations Reinvigorates the Immune Response for Enhanced Cancer Photo-Immunotherapy. Biomaterials (2021) 264:120451. doi: 10.1016/j.biomaterials.2020.120451

Conflict of Interest: The authors declare that the research was conducted in the absence of any commercial or financial relationships that could be construed as a potential conflict of interest.

Publisher's Note: All claims expressed in this article are solely those of the authors and do not necessarily represent those of their affiliated organizations, or those of the publisher, the editors and the reviewers. Any product that may be evaluated in this article, or claim that may be made by its manufacturer, is not guaranteed or endorsed by the publisher.

Copyright $\odot 2021$ Jiang, Liu, Tian, Zhuang, Piao, Gao, Tam, Hu and Cheng. This is an open-access article distributed under the terms of the Creative Commons Attribution License (CC BY). The use, distribution or reproduction in other forums is permitted, provided the original author(s) and the copyright owner(s) are credited and that the original publication in this journal is cited, in accordance with accepted academic practice. No use, distribution or reproduction is permitted which does not comply with these terms. 